\title{
EFFECTS OF SOME PHOSPHATIDYL COMPOUNDS ON BOAR SPERMATOZZOA FOLLOWING COLD SHOCK OR SLOW COOLING
}

\author{
WENDY J. BUTLER AND T. K. ROBERTS* \\ A.R.C. Unit of Reproductive Physiology and Biochemistry, \\ 307 Huntingdon Road, Cambridge CB3 $07 Q$
}

(Received 9th October 1974)

Rapid cooling of the spermatozoa of most mammalian species leads to irreversible decrease in motility and metabolism (Milovanov, 1934; Chang \& Walton, 1940), leakage of intracellular proteins and enzymes (Mann \& Lutwak-Mann, 1955 ), increase in the proportion of differentially stained cells (Easley, Mayer \& Bogart, 1942) and changes in cellular cation concentrations (Blackshaw \& Salisbury, 1957). These effects could all result from changes in permeability which suggests that the cell membrane is the principal target of injury. The visible disruption of membranes, particularly in the acrosomal region (Hancock, 1952), supports this hypothesis. Phospholipids are of major importance in membrane structure and ram, bull and boar spermatozoa are known to release phospholipid into the surrounding medium on cold shock and freezing (DarinBennett, Poulos \& White, 1973).

Various compounds, most notably milk and egg yolk, have been added to semen diluents in attempts to overcome the effects of cold-shock, with some success (Lardy \& Phillips, 1939; Thacker \& Almquist, 1953). These compounds are rich sources of phospholipids and it has been shown that lecithin is probably the active component in egg yolk which protects bull spermatozoa (Kampschmidt, Mayer \& Herman, 1953).

Whole ejaculate boar spermatozoa (without protective additives) are sensitive to cooling per se and contrast with those of other species in that increasing numbers are killed as the temperature is reduced below $15^{\circ} \mathrm{C}$. Boar epididymal spermatozoa are much more resistant than ejaculated spermatozoa to cooling and, in common with those of other species, are also more resistant to cold shock (Lasley \& Bogart, 1944a; Lasley \& Mayer, 1944). As spermatozoa pass through the epididymis and ductus deferens and are ejaculated, their resistance to cold shock is gradually reduced (Lasley \& Bogart, 1944b) and is accompanied by a decrease in cellular phospholipid (Grogan, Mayer \& Sikes, 1966; Quinn \& White, 1967). There is some evidence that the seminal plasma may be involved in increasing the sensitivity of ejaculated spermatozoa to temperature reduction. Spermatozoa from the sperm-rich fraction, which contains only a low proportion of seminal plasma, are less sensitive to cooling than those from the whole ejaculate (Pursel, Johnson \& Rampacek, 1972).

\footnotetext{
* Present address: Department of Biological Sciences, University of Newcastle, N.S.W. 2308, Australia.
} 
Certain protein components of the seminal plasma have been shown to precipitate progressively as the temperature is reduced from $14^{\circ} \mathrm{C}$ to $4^{\circ} \mathrm{C}$ (Roberts, Boursnell \& Brown, 1974). Roberts \& Boursnell (1974) have shown that addition of phosphatidyl compounds to boar seminal plasma markedly increased this precipitation. It is possible that, during cooling of whole semen, the plasma proteins compete with the spermatozoa for the available phospholipid. Phosphatidyl compounds were therefore added to whole semen before cooling in an attempt to increase sperm survival.

Phosphatidylcholine, phosphatidylserine and phosphatidylethanolamine were each suspended at $10 \mathrm{~mm}$ concentration in a diluent containing, per $100 \mathrm{ml}$, lactose $(4 \mathrm{~g})$, tris $(2 \mathrm{~g})$, citric acid $(1.15 \mathrm{~g})$ and fructose $(0.5 \mathrm{~g})$. Aliquots $(300 \mu \mathrm{l})$ of whole ejaculate were added to $100 \mu \mathrm{l}$ diluent containing phospholipid in thin-walled glass test-tubes $(1.0 \mathrm{~cm}$ i.d.) at room temperature. The final concentration of phospholipid in the diluted semen was $2.5 \mathrm{~mm}$. Semen added to diluent without phospholipid was included as a control and all treatments were carried out in triplicate. After various periods of equilibration at room temperature, the tubes were placed in a water-bath at $30^{\circ} \mathrm{C}$ for $10 \mathrm{~min}$ and were then plunged directly to $5^{\circ} \mathrm{C}$ and held there for $15 \mathrm{~min}$. The tubes were subsequently rewarmed to $30^{\circ} \mathrm{C}$ and the $\%$ motile spermatozoa was estimated. Assessment of acrosome morphology was also carried out using spermatozoa from the same samples that had been fixed in formol-saline (100 spermatozoa/ sample were assessed using phase-contrast microscopy and the percentage with

Table 1. The effect of various phosphatidyl compounds and equilibration time before cold shock on $\%$ motile spermatozoa and the \% spermatozoa with normal acrosomes following exposure

\begin{tabular}{lccccc}
\hline & \multicolumn{5}{c}{ Equilibration time before cold shock (hr) } \\
\cline { 2 - 6 } \multicolumn{1}{c}{\begin{tabular}{c} 
Suspermding medium \\
\cline { 2 - 6 }
\end{tabular}} & 0 & $\frac{1}{2}$ & $1 \cdot 0$ & $2 \cdot 0$ & $4 \cdot 0$ \\
\hline Diluent alone & $10 \cdot 6$ & $10 \cdot 6$ & $16 \cdot 1$ & $22 \cdot 2$ & $21 \cdot 7$ \\
& $(1 \cdot 3)$ & $(1 \cdot 7)$ & $(1 \cdot 0)$ & $(5 \cdot 3)$ & $(5 \cdot 0)$ \\
Diluent & $13 \cdot 3$ & $36 \cdot 6$ & $76 \cdot 1^{*}$ & $80 \cdot 0^{*}$ & $77 \cdot 8^{*}$ \\
+ phosphatidylserine & $(0 \cdot 7)$ & $(4 \cdot 3)$ & $(6 \cdot 7)$ & $\left(22 \cdot 0^{*}\right)$ & $(9 \cdot 3)$ \\
Diluent & $6 \cdot 1$ & $7 \cdot 2$ & $11 \cdot 1$ & $14 \cdot 4^{*}$ & $7 \cdot 8^{*}$ \\
+ phosphatidylcholine & $(0 \cdot 3)$ & $(1 \cdot 3)$ & $(6 \cdot 0)$ & $(4 \cdot 3)$ & $(4 \cdot 3)$ \\
Diluent & $10 \cdot 6$ & $11 \cdot 1$ & $14 \cdot 5$ & $21 \cdot 7$ & $25 \cdot 0$ \\
+ phosphatidylethanolamine & $(0 \cdot 3)$ & $(2 \cdot 0)$ & $(2 \cdot 7)$ & $(5 \cdot 7)$ & $(3 \cdot 0)$ \\
& & & & & \\
\hline
\end{tabular}

Figures in parentheses are the $\%$ of spermatozoa with normal acrosomes.

* Within each equilibration period, values are significantly $(P<0.001)$ different from those of spermatozoa suspended in diluent alone.

normal acrosomes was determined). The results are shown in Table 1. Similar results were obtained when the diluted semen was cooled slowly to $5^{\circ} \mathrm{C}$ over a period of 3 to $4 \mathrm{hr}$.

Among the compounds examined, phosphatidylserine alone protected the spermatozoa against the damaging effects of exposure to cold. Equilibration at room temperature for approximately $1 \mathrm{hr}$ was required to obtain the maximum protective effect. The semen in diluent without phospholipid also gradually 
increased in resistance to cold shock as the time before treatment lengthened. A similar effect was noted in whole semen in the absence of diluting media (Pursel et al., 1972). In an attempt to distinguish between these effects, semen samples were held at room temperature for various periods before cold shock; phosphatidylserine was either present throughout the equilibration or it was added immediately before cold shock and undiluted controls (without phosphatidylserine) were also included. The cold-shock procedure has been described above and the results are shown in Table 2.

Table 2. The effect of time of addition of phosphatidylserine and equilibration before cold shock on $\%$ motile spermatozoa following exposure

\begin{tabular}{lcccccccc}
\hline & \multicolumn{7}{c}{ Equilibration time before cold shock $(h r)$} \\
\cline { 2 - 8 } \multicolumn{1}{c}{$\begin{array}{c}\text { Time of addition } \\
\text { of phosphatidylserine }\end{array}$} & 0 & $\frac{1}{2}$ & $1 \cdot 0$ & $1 \cdot 5$ & $2 \cdot 0$ & $3 \cdot 0$ & $4 \cdot 0$ \\
\hline $\begin{array}{l}\text { None added (undiluted semen) } \\
\text { Before equilibration }\end{array}$ & 15 & $20^{\mathrm{a}}$ & $23 \cdot 9^{\mathrm{a}}$ & $27 \cdot 2^{\mathrm{a}}$ & $26 \cdot 7^{\mathrm{a}}$ & $22 \cdot 8^{\mathrm{a}}$ & $25 \cdot 6^{\mathrm{a}}$ \\
$\begin{array}{l}\text { After equilibration } \\
\text { (before cold shock) }\end{array}$ & $18 \cdot 3$ & $53 \cdot 4^{\mathrm{b}}$ & $58 \cdot 6^{\mathrm{b}}$ & $64 \cdot 5^{\mathrm{b}}$ & $63 \cdot 3^{\mathrm{b}}$ & $65 \cdot 0^{\mathrm{b}}$ & $68 \cdot 6^{\mathrm{b}}$ \\
& $18 \cdot 3$ & $35 \cdot 5^{\mathrm{c}}$ & $47 \cdot 2^{\mathrm{c}}$ & $61 \cdot 7^{\mathrm{b}}$ & $65 \cdot 0^{\mathrm{b}}$ & $62 \cdot 2^{\mathrm{b}}$ & $63 \cdot 8^{\mathrm{b}}$ \\
\hline
\end{tabular}

Within each equilibration period, different letters indicate significant differences $(P<0.001)$.

The beneficial effect of equilibration may be associated with changes in the sperm membrane which increase its resistance to cold shock. The resistance is much enhanced by the presence of phosphatidylserine which accelerates the attainment of the maximum resistance if present throughout the equilibration, or acts immediately if added after equilibration.

The diluent used for suspending the phospholipids did confer some resistance to cold shock on the spermatozoa compared to those in undiluted semen. To ensure that the action of the phosphatidylserine was not dependent on the presence of this diluent, sperm Ringer (Mann, 1964), 300 mM-sucrose, $2 \%$ sodium citrate and tris-buffered saline were also used as media. In each case, the beneficial effect of the presence of phosphatidylserine was apparent.

In order to determine more precisely the concentration of phosphatidylserine required to protect the spermatozoa, it was added at $0 \cdot 125-, 0 \cdot 25-, 0 \cdot 5-, 1 \cdot 0$ - or $2 \cdot 0-\mathrm{mm}$ final concentration to semen from two boars and cold-shock treatment was carried out approximately $1 \frac{1}{2} \mathrm{hr}$ after collection of the semen. More than $60 \%$ motile spermatozoa survived cold shock with a final concentration of 0.5 mm-phosphatidylserine in the diluted semen. This was significantly $(P<0.001)$ higher than with a concentration of $0.25 \mathrm{~mm}$, or below. Increasing the concentration of phosphatidylserine above $0.5 \mathrm{~mm}$ did not significantly increase the motility. The pattern of response in terms of $\%$ spermatozoa with normal acrosomes was similar but, in each case, was not as high as the $\%$ motile spermatozoa. No significant differences were observed between the two boars.

These comparisons were carried out using a single batch of phosphatidylserine (B.D.H. Chemicals, Poole, Dorset). When comparisons between various concentrations of two different batches were carried out, using semen from one boar, highly significant differences $(P<0.001)$ between the batches in their effectiveness in protecting against cold shock were observed. One batch gave 
maximum protection in terms of motility at a final concentration of $0.5 \mathrm{~mm}$ while similar protection with the other batch was not achieved until a concentration of $1.0 \mathrm{~mm}$ was used. At concentrations above $1.0 \mathrm{~mm}$ in the diluted semen, both batches conferred equally high resistance on the spermatozoa. It is possible that this apparent difference in concentration requirements is merely a reflection of biological variation between the sources of the phospholipid or variation in extraction procedure.

Since phosphatidylserine is an unstable compound and may undergo changes during preparation, its effectiveness in protecting against cold shock was compared directly with that of the related compounds, phosphatidic acid, L-serine and DL-O-phosphoserine. Each compound was suspended in the original diluent at $10 \mathrm{~mm}$ concentration giving a final concentration of $2.5 \mathrm{~mm}$ in the diluted semen. The semen in which phosphatidylserine was present during cold shock retained $60 \%$ motile spermatozoa. This was significantly $(P<0.001)$ higher than the $30 \%$ or less of motile spermatozoa in semen containing the other compounds, though their presence did increase $(P<0.05)$ the motility after cold shock compared with samples in diluent alone $(21 \%$ motile) and undiluted semen $(13 \%$ motile). The semen with phosphatidylserine present also showed a non-significantly higher percentage of spermatozoa with normal acrosomes, $22 \%$ compared with $12 \%$ or less for the other compounds and the controls.

The action of phosphatidylserine in protecting boar spermatozoa against cold shock appears to be a specific function of this substance since other phosphatidyl and related compounds were ineffective. Boar seminal haemagglutinin inhibition tests (Roberts \& Boursnell, 1974) have also shown considerable variations related both to the phosphatidyl compound and the red cell species employed. These observations strengthen the view that the precise conditions necessary for protection of the spermatozoa probably reflect particular structural features of the sperm membrane. Such structural features may be unique to each species; preliminary investigations with bull and ram spermatozoa indicate that the protective effects of phosphatidyl compounds against cold shock in spermatozoa are markedly species-specific.

The authors wish to thank Dr C. Polge and Dr J. C. Boursnell for their valuable advice and encouragement and Miss S. E. Winsor for technical assistance. This work was aided by a grant from the Meat and Livestock Commission and the receipt of an RGVS Trust Fund, Senior Fellowship in Animal Health by one of us (T.K.R.) is gratefully acknowledged.

\section{REFERENCES}

Blackshaw, A. W. \& Salisbury, G. W. (1957) Factors influencing metabolic activity of bull spermatozoa. II. Cold-shock and its prevention. F. Dairy Sci. 40, 1099-1106.

Chang, M. C. \& Walton, A. (1940) The effects of low temperature and acclimatization on the respiratory activity and survival of ram spermatozoa. Proc. $R$. Soc. B, 129, 517-527.

Darin-Bennetr, A., Poulos, A. \& White, I. G. (1973) The effect of cold shock and freeze-thawing on release of phospholipids by ram, bull, and boar spermatozoa. Aust. F. biol. Sci. 26, 1409-1420.

EAsLey, G. T., MAYER, D. T. \& Bogart, R. (1942) The influence of diluters, rate of cooling and storage temperatures upon survival of sperm. Am. F. vet. Res. 3, 358-363. 
Grogan, D. E., Mayer, D. T. \& Sikes, J. D. (1966) Quantitative differences in phospholipids of ejaculated spermatozoa and spermatozoa from three levels of the epididymis of the boar. 7. Reprod. Fert. 12, 431-436.

Hancock, J. L. (1952) The morphology of bull spermatozoa. F. exp. Biol. 29, 445-453.

Kampschmidt, R. F., MAYER, D. T. \& Herman, H. A. (1953) Lipid and lipoprotein constituents of egg yolk in the resistance and storage of bull spermatozoa. 7. Dairy Sci. 36, 733-742.

Lardy, H. A. \& Phillirs, P. H. (1939) Preservation of spermatozoa. Proc. Am. Soc. Anim. Prod., 32nd A. Meting, 219-221.

LASLEY, J. F. \& BogarT, R. (1944a) A comparative study of epididymal and ejaculated spermatozoa of the boar. F. Anim. Sci. 3, 360-370.

LASLEY, J. F. \& Bogart, R. (1944b) Some factors affecting the resistance of ejaculated and epididymal spermatozoa of the boar to different environmental conditions. Am. F. Physiol. 141, 619-624.

LASLEY, J. F. \& MAYER, D. T. (1944) A variable physiological factor necessary for the survival of bull spermatozoa. F. Anim. Sci. 3, 129-135.

Mann, T. (1964) The Biochemistry of Semen and of the Male Reproductive Tract, p. 347. Methuen, London.

MANN, T. \& LUTWAK-MANN, C. (1955) Biochemical changes underlying the phenomenon of cold-shock in spermatozoa. Archs Sci. biol. 39, 578-588.

Milovanov, V. K. (1934) Osnovy Iskusstvenuogo Oseminija. [Principles of Artificial Insemination.] State Publishing House, Moscow and Leningrad. In Russian.

Pursel, V. G., Johnson, L. A. \& Rampacek, G. B. (1972) Acrosome morphology of boar spermatozoa incubated before cold shock. F. Anim. Sci. 35, 580-584.

Quinn, P. J. \& White, I. G. (1967) Phospholipid and cholesterol content of epididymal and ejaculated ram spermatozoa and seminal plasma in relation to cold shock. Aust. F. biol. Sci. 20, 1205-1215.

RoberTs, T. K. \& Boursnele, J. C. (1974) The inhibitory action of phosphatidyl compounds on boar seminal haemagglutinin. F. Reprod. Fert. 41, 489-492.

Roberts, T. K., Boursneli, J. C. \& Brown, A. D. (1974) The rôle of zinc in promoting the opalescence and cold precipitation of boar seminal plasma. II. Relationship of a zinc-precipitable protein with the haemagglutinin. F. Reprod. Fert. 37, 373-386.

Thacker, D. L. \& Almquist, J. O. (1953) Diluters for bovine semen. I. Fertility and motility of bovine spermatozoa in boiled milk. F. Dairy Sci. 36, 173-180. 